\title{
A EVOLUÇÃO DO CONCEITO DE FILIAÇÃO E SUA APLICAÇÃO NA SOCIEDADE MANAUENSE
}

\author{
M. S. Coelho' e A. P. N. Garcia' \\ 'Universidade Nilton Lins - Curso de Direito \\ mateusscoelho@hotmail.com
}

Artigo submetido em fevereiro/2012 e aceito em fevereiro/2013

\section{RESUMO}

Um dos assuntos atuais põe em pauta os direitos da família, em relação aos pleitos na esfera política, social e no terceiro setor da sociedade brasileira quanto à questão do vínculo da filiação em exemplos de famílias não convencionais, tais como: adoções homoafetivas, adoções entre casais convencionais, filhos oriundos de inseminação artificial etc. Nestes aspectos, surgem na esfera jurídica entendimentos antagônicos quanto à fiel aplicação do conceito de filiação, e sua aplicação em processos cíveis e nas varas de família. Diante disso, neste trabalho é apresentado um relato quanto ao histórico da evolução do conceito de filiação, sobretudo no Brasil, e nas mais diferentes aplicações em processos judiciais, relatos técnicos e comunicações informais. Sendo feito um paralelo aos tipos de filiação e a correlação com a legislação vigente. O estudo caracteriza-se como exploratório-descritivo, sendo feita uma pesquisa, numa amostra fortuita, no universo dos advogados de família quanto ao entendimento sobre questões polêmicas e de difícil entendimento. Dessa pesquisa, observou-se que a favorabilidade ao entendimento das exceções ao conceito de filiação envolve $17 \%$ dos profissionais pesquisados.

PALAVRAS-CHAVE: Filiação, Brasil e Família.

\section{THE EVOLUTION OF THE CONCEPT OF MEMBERSHIP AND ITS APPLICATION IN SOCIETY MANAUENSE}

\begin{abstract}
One of the most recent subjects related to family rights, being guideline of lawsuits in the politics, social and in the third sector boundaries of the Brazilian society. It regards the question of affiliation in non-conventional families, such as: homo-affection adoptions, adoptions between conventional couples, children born from artificial insemination etc. In these points, there are legal antagonistic agreements about the application of the concept of affiliation, and its application in family court processes. This article reports a historic description from the evolution of the affiliation concept, focused in Brazil, considering the most different
\end{abstract}

applications in law sue processes, technical reports and informal memos. A parallel with the types of affiliation and other correlations with the current law have already been made. Moreover, a research was made, with a fortuitous sample, in the universe of family expert lawyers about their understanding regarding this questions and controversies, as well as issues of difficult agreement. It was concluded that a positive agreement regarding the exceptions of the affiliation concept involves $17 \%$ of the asked professionals, as well as women professionals are more sensible in the acceptance of the subject.

KEY-WORDS: Affiliation, Brazil and Family. 


\section{A EVOLUÇÃO DO CONCEITO DE FILIAÇÃO E SUA APLICAÇÃO NA SOCIEDADE MANAUENSE}

\section{INTRODUÇÃO}

Um dos assuntos atuais, sobretudo pelas recentes aprovações na Câmara Federal e Tribunais de Justiça, põe em discussão os direitos da família, sendo pauta de pleitos na esfera política, social e no terceiro setor da sociedade brasileira, diz respeito à questão do vínculo da filiação em exemplos de famílias não convencionais, tais como: adoções homoafetivas, adoções entre casais convencionais, filhos oriundos de inseminação artificial etc.

Além disso, a evolução da engenharia genética, sobretudo com o desenvolvimento da procriação in vitro, delineia um novo cenário de formação familiar no estado civil brasileiro. Gerando pleitos e dúvidas sobre o relacionamento direto nestes processos que envolvem o vínculo da filiação.

Frente a esses cenários existem dificuldades no entendimento legal, por alguns juristas, em definir claramente tais conceitos. Logo, questões que envolvem monta financeira, disputas por bens e mesmo direitos de casais não convencionais ganham a tona, e merecem um tratamento diferenciado. Nestes pontos, surgem na esfera jurídica entendimentos antagônicos quanto à fiel aplicação do conceito de filiação, e sua aplicação em processos cíveis e nas varas de família. Tais discussões variam em questões que envolvem pleitos de heranças, paternidade, maternidade e os diferentes elementos dos direitos sociais.

Diante disso, neste trabalho é apresentado um relato quanto ao histórico da evolução do conceito de filiação, sobretudo no Brasil, e nas mais diferentes aplicações em processos judiciais, relatos técnicos e comunicações informais. Sendo feito um paralelo aos tipos de filiação e a correlação com a legislação vigente. Além disso, é feito um estudo exploratório-descritivo, numa amostra fortuita (ou seja, escolhida de forma aleatória e pontual, em meio de diferentes atores do direito), no universo dos advogados de família quanto ao entendimento sobre questões polêmicas e de difícil entendimento.

Sob tal ótica, alguns questionamentos foram avaliados com esse trabalho, a saber: aplicação do conceito da filiação entre os advogados da área de família de Manaus-AM, entendimento sobre as adoções não convencionais, as principais dúvidas que pairam no uso de técnicas de reprodução assistida pela engenharia genética, a atuação e opinião direta dos advogados sobre a polêmica que envolve o tema, e, por fim, a correlação desses fatores ao sexo, idade e estado civil dos profissionais pesquisados.

Sendo assim, espera-se que com este trabalho se possa contribuir de alguma forma com um melhor entendimento e direcionamento das rotas de melhorias para atenuar a situação daqueles que esperam pela manifestação do Estado na formatação e desenvolvimento de uma família. Mais especificamente com relação ao modelo entendido pelas estruturas jurídicas da sociedade manauense. Em resumo, o presente estudo pretende buscar resposta para a seguinte pergunta de pesquisa: Como evoluiu o conceito de filiação e como vem sendo tratados e entendidos pelos advogados, que atuam em Manaus-AM, os casos de filiação homoafetiva, inseminações artificiais e pedidos de guardas em processos de adoção? Em suma, teve-se como objetivo a identificação da evolução do conceito de filiação na história da evolução humana e, sobretudo na legislação brasileira, bem como, traçando um perfil mínimo da sua aplicação atual na sociedade manauense. 


\section{EVOLUÇÃO DO CONCEITO DE FILIAÇÃO}

Em meados do século XX, segundo Bevilaqua (1956), o conceito de filiação é a relação de parentesco existente entre a prole e os progenitores considerando o fluxo dos filhos para seus imediatos ascendentes, se desdobrando em sub-conceitos tais como os de paternidade e maternidade, que consideraram descensionalmente, do pai ou mãe para o filho. Consistindo numa relação estritamente derivada do conceito biológico da relação humana.

O conceito se mantém fortalecido em momentos distintos da política brasileira, em especial na esfera do direito da família. Em relatos, como o de Barros Monteiro (1978), se mantém o conceito de relação que existe entre o filho e as pessoas que o geraram. Garantindo-se o sentido inverso, isto é, do lado dos genitores referentemente ao filho, essa relação chama-se paternidade ou maternidade.

Considerando a evolução política nacional, em especial com a publicação da nova constituição em meados de 1988, o conceito definido por Rodrigues (1991) já estabelece um detalhamento sobre o conceito, enquanto uma relação de parentesco consanguíneo, em primeiro grau e em linha reta, que liga uma pessoa àquelas que o geraram, mantendo-se o aspecto biológico e reforçando o aspecto genético e heranças como as características sanguíneas no conceito. Neste trabalho, comenta-se ainda que essa relação de parentesco, dada a proximidade de grau, cria um sem-número de efeitos no campo do direito, daí derivando a importância de sua verificação. Ademais, dada à variedade de consequências, confirme a filiação seja legítima ou ilegítima, torna-se altamente relevante provar e estabelecer a legitimidade, daí a inclusão de técnicas genéticas, tais como o tipo sanguíneo para tal definição.

Leite (1994) iniciada uma nova discussão sobre o conceito, com uma definição, onde, singelamente, estabelece o conceito da relação ou vínculo (onde se inicia a utilização de uma derivação da relação, enquanto o termo vínculo, dando-se aberturas ao rígido conceito direto de serem consanguíneos) que une "gerados" e "geradores", e faz uma abrangência enquanto o "laço de descendência que existe entre duas pessoas, das quais um é pai ou a mãe da outra'. Neste mesmo trabalho, o autor faz uso de conceitos de outros tais como Planiol e Ripert, que definem a filiação, na ótica do profundo estudioso da matéria Mário Aguiar Moura, como sendo o conceito triangular irredutível, sob o aspecto natural, ou seja, a relação imediata do pai, ou da mãe da criança. E a abertura do conceito é externada quando cita que 'Pode não sê-lo desde o ponto de vista jurídico formal', diz Aguiar Moura, sabido que a lei estabelece restrições ou ampliações mais ou menos arbitrárias. Mas, no contexto natural, envolve a paternidade propriamente dita e a maternidade, premissas de que é resultante a filiação. Nem sequer os audaciosos avanços da ciência médica obtendo a concepção em laboratório, fogem dessa triangularidade. É do encontro em época oportuna da célula masculina com o óvulo para a formação do ovo, ainda que fora das trompas, que se dá o fenômeno transcendental do surgimento de uma nova vida. É a consequência da combinação indissociável das duas partes que independente antes, se unificaram na síntese da criação. Essa simbiose opera no sentido de serem os filhos alguma coisa dos pais, sem deixarem de ser eles mesmos como personalidades independentes.

Apesar das evoluções tecnológicas e sociais, o conceito ainda é mantido na pós-nova constituição, e autores como Monteiro (1996) exprime o conceito como sendo a relação que existe entre o filho e as pessoas que o geraram. Encarada em sentido inverso, isto é, do lado dos genitores referentemente ao filho, essa relação chama-se paternidade ou maternidade, mantendo-se a leitura dos anos 50 do século XX. O reforço do conceito biológico é enfatizado por 
Pereira (1996), quando define o conceito como um fenômeno excepcionalmente complexo, antes de tudo biológico, onde examinado pelos cientistas como forma de perpetuação das espécies. Abre a relação direta com um fenômeno fisiológico, onde se gera um objeto de indagações sociológicas e históricas, sendo no aspecto científico um capítulo da Higiene e da Eugenia. Porém, tal discussão acaba por pertencer, na visão do autor, ao mundo físico e ao mundo moral (Dusi), onde em seus relatos este exprime simplesmente o fato do nascimento e a situação de ser filho, e, num desenvolvimento semântico dentro da Ética, traduz um vínculo jurídico. Sendo assim, compreende-se simultaneamente o fato concreto da procriação e uma relação de direito. Sendo iniciada a necessidade do precedente técnico na definição moral e ética na escolha de valores.

Veloso (1997) mantém o conceito da relação de parentesco que se estabelece entre pais e filhos; como a principal e mais próxima relação de parentesco, havendo um entendimento direto para o desdobramento original do conceito de filiação. Da mesma forma, Silva (2000) segue a mesma postura de entendimento que a formação original do conceito, estabelecendo que o termo deva ser empregado para distinguir a relação de parentesco que se estabelece entre as pessoas que deram vida a um ente humano e este.

Boscaro (2002) estabelece em seu conceito o detalhamento entre a relação que une uma pessoa àquelas que a geraram, não se restringindo ao aspecto genético. Um novo desdobramento do conceito é feito por Nery Junior (2002), onde estabelece como sendo que o estado familiar da pessoa que decorre do fato ou do direito (inovação deste conceito) e, uma vez legalmente estabelecido, faz emergir poderes e deveres de que decorrem efeitos a partir do nascimento, ainda que somente a posteriori a filiação seja declarada estabelecida, em especial, gera dúvidas quanto a relações da filiação de seres gerados por técnicas de proveta ou mecanismos genéticos desenvolvidos mais acentuadamente na década de 90 do século XX.

Em meio ao desenvolvimento tecnológico e novas adoções de políticas sociais, conceitos retrógrados como são encontrados, como, por exemplo, Rodrigues (2002), ainda mantém a filiação como sendo um conceito rígido e de origem natural, como sendo a relação de parentesco consanguíneo, em primeiro grau e em linha reta, que liga uma pessoa àquelas que a geraram, ou a receberam como se as tivessem gerado.

E o pensamento do conceito rígido é fracionado severamente por Venosa (2003), quando estabelece que é, destarte, um estado, o status familiae, tal como concebido pelo antigo direito, e, onde todas as ações que visam o seu reconhecimento, modificação ou negação, e são, portanto, ações de estado. Ou seja, para o autor o termo filiação exprime a relação entre o filho e seus pais, aqueles que o geraram ou o adotaram. Sendo, então, estabelecido no conceito de filiação um paradigma entre o grau biológico e o grau afetivo, incorporando-se ao conceito uma nova variável para definição da filiação.

Lobo (2004) não menos conservativo abre o conceito para uma nova realidade, o aumento significativo da volatilidade com que os relacionamentos se desfazem e os meios pelos quais os novos seres são gerados. Nesta relação de parentesco se estabelece entre duas pessoas, uma das quais é considerada filha da outra (pai ou mãe) pura e simplesmente.

O aspecto social e as novas tecnologias de procriação se incorporam e se fundamentam de forma clara em Diniz (2005-A), quando a autora estabelece que o liame que existe entre ascendente e descendente, em linha reta de primeiro grau, pode ser: consanguíneo ou não, não havendo necessidade da união sexual, vez que também pode ser decorrente de inseminação artificial homóloga e heteróloga fecundação in vivo, de implantações de embriões homólogos e 
heterólogos fecundação in vitro, bem como de adoção. Neste momento, surge um forte conceito da desassociação da necessidade de união sexual, podendo-se entender como uma tentativa a validar casos de relações com membros do mesmo sexo, que poderiam ser encarados com um grau que culminaria com uma filiação.

Diniz (2005-B) ratifica os meios de fecundação e os vínculos sociais impostos, ao conceito. Onde estabelece que o vínculo existente entre pais e filhos; vem a ser a relação de parentesco consanguíneo em linha reta de primeiro grau entre uma pessoa e aquelas que lhe deram vida, podendo, ainda, (CC, arts. 1.593 a 1.597 e 1.618 e s.), ser uma relação socioafetiva entre pai adotivo e institucional e filho adotado ou advindo de inseminação artificial heteróloga. Consolidando as preocupações anteriores sobre os novos conceitos oriundos dos novos meios de formação do vinculo paternal ou maternal.

A relação de parentesco por meio da origem legal, como no caso de adoção ou reprodução assistida com utilização de material genético de pessoa estranha ao casal é também descrito nos conceitos interpretados por Scalquette (2005), estando aderente a série evolutiva do conceito. Generalizando o conceito original Klinger Filho (2007) avança no conceito com a inclusão ao termo de filiação (àquelas que a geraram), do adendo "ou a receberam como se tivessem gerado". Neste conceito, generalizam-se os tipos de relações e gera-se uma expectativa maior para os novos modelos de família que a sociedade moderna inicia-se por estabelecer.

O mesmo conceito modernizado é descrito por Lobo (2008, p. 192) como sendo: "É a relação de parentesco que se estabelece entre duas pessoas, uma das quais nascidas da outra, ou adotada, ou vinculada mediante posse de estado de filiação ou por concepção derivada de inseminação artificial heteróloga [...]". Ou seja, sob o ponto de vista do direito brasileiro, a filiação é biológica ou não biológica - sendo um fato jurídico e não proposições informais. E por ser uma construção cultural, resultante da convivência familiar e da afetividade, o direito a considera como um fenômeno socioafetivo, incluindo a de origem biológica, que antes detinha a exclusividade, definitivamente.

Gonçalves (2009) utiliza do novo conceito e estabelece na sua leitura sobre o tema, que a filiação consiste na relação de parentesco consanguíneo, em primeiro grau e em linha reta, que liga uma pessoa àquelas que a geraram, ou a receberam como se a tivessem gerado; validando o novo modelo sociocultural.

Apesar da evolução do conceito a discussão ainda rende frentes antagônicas, tais como Candido (2010), que mantém aceso o conceito fundado no fato da procriação, pelo qual se evidencia o estado de filho, indicativo do vínculo natural ou consanguíneo, firmado entre gerado e progenitores. É assim, a relação de parentesco entre pais e os filhos, considerados na ordem ascensional, destes para os primeiros, do qual também procedem, em ordem inversa, os estados de pai (paternidade) e de mãe (maternidade).

Fontes atuais mantêm o conceito modernizado, tais como Cavallini (2010), que traduz o conceito no elo que há entre pai-mãe e filho, sendo biológico ou afetivo, não tendo exigência da união sexual, permitindo-se sua concretização através da adoção, inseminação artificial e implantação de embriões.

A partir dos fatos expostos acima, a filiação é a relação de parentesco biológica e afetiva entre pais e filhos. Visto que relação significa o laço existente entre algo ou alguém, neste caso entre pais e filhos. Portanto, filiação é o laço caracterizado não só dos pais com aqueles em que deram origem, mas sim dos pais com aqueles que possuem uma ligação sentimental, de afeto e 
carinho.

\section{METODOLOGIA}

O estudo constitui-se de uma pesquisa aplicada, pois objetiva levar conhecimentos para extensão do conceito de filiação, e sua aplicação no município de Manaus-AM. Do ponto de vista dos objetivos, trata-se de um estudo exploratório-descritivo, o qual visa descrever a problemática em discussão, buscando caracterizar o objeto de estudo. Do ponto de vista dos procedimentos técnicos, o estudo caracteriza-se como pesquisa bibliográfica, por sua elaboração partir do levantamento e análise de material já publicado, em artigos científicos, livros, relatórios técnicos, etc. (SILVA; MENEZES, 2001), e como estudo de caso devido à utilização de dados de campo, com observação assistemática não-participante, in loco.

A estrutura da pesquisa consiste em:

- Formulação do problema, englobando a justificativa do estudo, a determinação dos objetivos, a contextualização da problemática e definição da metodologia;

- Realização do levantamento teórico, que orienta a caracterização do objeto de estudo, as definições e conceitos a serem utilizados em análise e correntes de pensamentos que norteiam a hipótese da pesquisa;

- Levantamento de dados em campo, por meio da aplicação dos questionários;

- Estudo criterioso sobre os princípios do direito e conceitos associados.

Os dados coletados em campos foram organizados, de acordo com a necessidade da utilização em pesquisa, e utilizados para elaboração do levantamento das principais ações de oportunidades.

Em termos de hipóteses levantadas no presente estudo foram testadas quatro, conforme listadas abaixo:

- Hipótese 1: os advogados consultados tendem a ter posicionamento diferenciado para casos que envolvem pleitos de filiação para casais homoafetivos compostos por mulheres e homens, estando negada a paternidade ou maternidade para a maioria dos casos.

- Hipótese 2: os julgamentos, em Manaus-AM, para questões de filiação onde a geração do feto se deu por meio de recursos de engenharia genética ou inseminação artificial, por um casal convencional, tendem a confirmação da relação de filiação, em especial, para os casos onde ocorre o cenário dos pais e filhos serem consanguíneos.

- Hipótese 3: existência de favorabilidade para a atualização dos mecanismos jurídicos para aceitação das referidas temáticas.

- Hipótese 4: a evolução do conceito de filiação tende a ser adaptado conforme a evolução tecnológica e as novas formas de bases familiares na sociedade manauense, sobretudo, com a aceitação desses de forma independente de idade, sexo e estado civil. 
O trabalho foi desenvolvido com base na pesquisa bibliográfica, com o respectivo fichamento dos principais artigos científicos, publicações informais e relatos de súmulas e outras derivações jurídicas. E foram aplicados questionários para consolidar a opinião de advogados que atuam em causas que envolvem varas da família, no município de Manaus-AM.

Quanto aos procedimentos técnicos, a pesquisa é do tipo levantamento de dados bibliográficos e aplicação de questionário padrão, porém, não considerada experimental visto que não se manipulou variáveis e utilizou-se de amostragem fortuita, filtrada apenas pelo local de aplicação, a saber: varas de família e escritórios especializados.

Quanto aos propósitos, a pesquisa teve caráter exploratório, porque procura identificar as variáveis que explicam o fenômeno sob investigação, e descritivo, além de descrever e interpretar a forma através da qual essas variáveis se relacionam com o fenômeno da filiação. Neste caso, fez-se uso de uma pesquisa para qualificação dos entrevistados, em termos da faixa etária, estado civil e sexo. A referida pesquisa foi aplicada no período de 27 a 29 de abril de 2011, não sendo afetada pela decisão do Superior Tribunal Federal quanto ao reconhecimento da união homoafetiva.

A pesquisa bibliográfica teve como objetivo identificar as variáveis explicativas do fenômeno da filiação entre os advogados que atuam em causas de família no município de Manaus-AM. Para isso, foram aplicados questionários em grupos de advogados encontrados nas principais varas de família do município de Manaus-AM, nos diferentes bairros da cidade (envolvendo-se as diferentes classes sociais).

Para o levantamento dos dados foram utilizadas ferramentas computacionais de buscas de súmulas, jurisprudências, sentenças, artigos técnicos e em mecanismos de circulação pública, para delinear o cenário evolutivo do conceito de filiação.

Assim como, foram aplicados questionários elaborados para este fim, tendo-se de forma padronizada e com o propósito de consolidar o perfil de entendimento e vertentes decisórias que compõe a leitura do tema, entre os principais advogados do segmento, na cidade de ManausAM.

O produto do levantamento bibliográfico foi tratado por meio do fichamento, e a geração de um texto descritivo do resumo dos dados obtidos com o referido referencial teórico e bibliográfico levantado.

Os dados dos questionários foram tabulados e tratados por meio de ferramentas de análise comparativa e estatística de forma a traçar o perfil da sociedade manauense, entre os principais envolvidos, sobre o tema filiação. Para isso, foi utilizado o software Microsoft Excel ${ }^{\circledR}$. Os resultados foram tratados e gerados gráficos do tipo histograma, barras e "pizza".

\section{RESULTADOS E DISCUSSÃO}

Neste tópico serão apresentados os resultados obtidos com os questionários aplicados e o tratamento estatístico dos dados obtidos. A caracterização dos entrevistados se deu pelas variáveis: faixa etária, estado civil e sexo. O quadro de entrevistados foi composto por 53 advogados, questionados nas diferentes Varas de Família da cidade de Manaus, Amazonas.

Em relação a idade, a amostragem realizada obteve um perfil de faixa etária bastante diversa, não tendendo a nenhum modelo de distribuição normal e sem uma média direta, entre os resultados. Entretanto, quando calculada a média aritmética obtém-se uma boa correlação ao 
valor da idade média da população economicamente ativa do Brasil, ou seja, valor no intervalo de 40 anos. Sendo com isso, entendido como uma amostra representativa ao cenário almejado. Na Figura 1, são apresentados os resultados desse cenário.

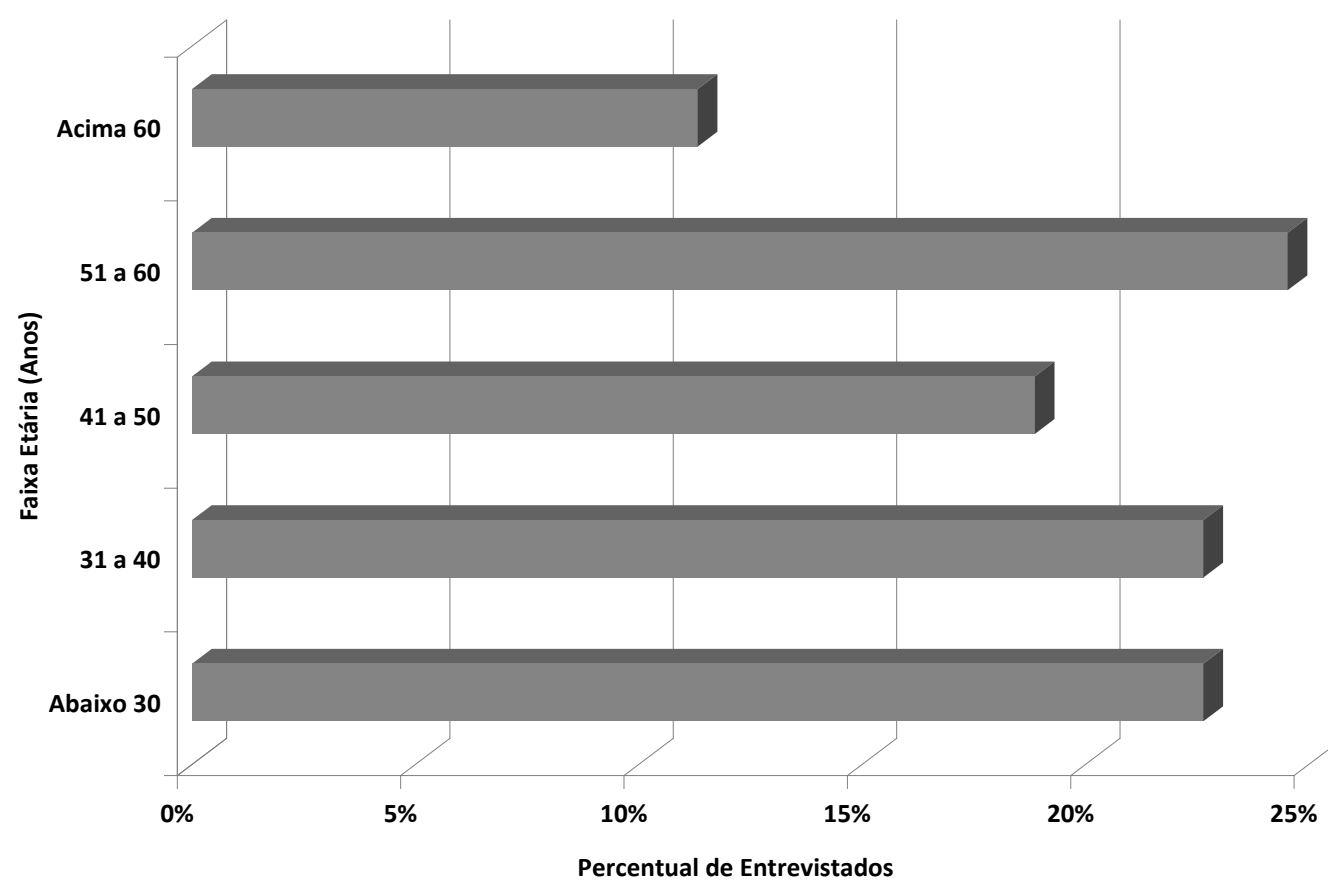

Figura 1 - Perfil das idades dos profissionais entrevistas.

$\square$ Casado
$\square$ Solteiro
$\square$ Divorciado
$\square$ União Estável

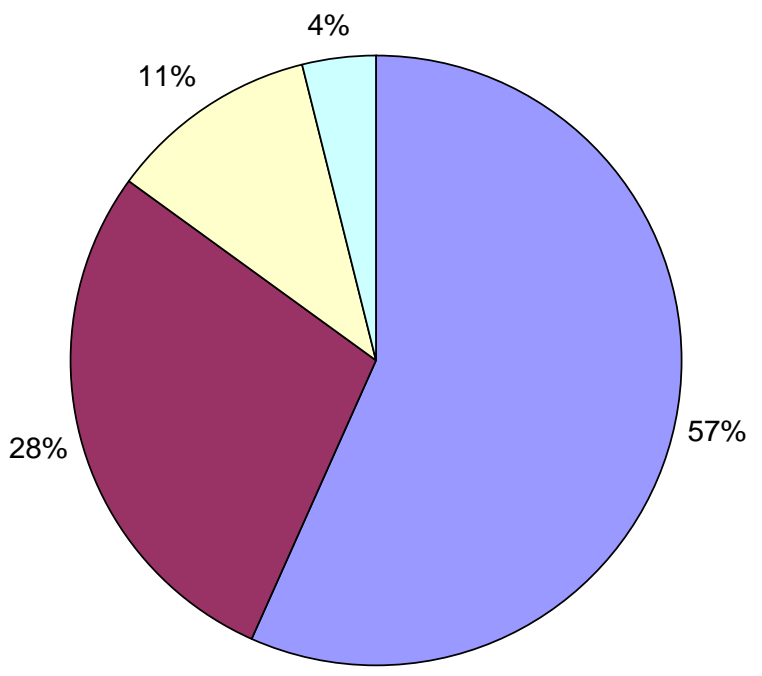

Figura 2 - Estado civil dos entrevistados.

Na Figura 2 são apresentados os resultados relativos ao estado civil dos entrevistados. É possível observar que a grande maioria dos profissionais pesquisados são casados, ou melhor, $57 \%$ desses. Nota-se, ainda, que pouco mais de $4 \%$ constam deslocados do processo convencional de união, mantendo união estável com o parceiro. De toda forma, a amostra apresentou ainda um percentual de $28 \%$ de profissionais solteiros. 
Com relação ao sexo dos entrevistados, a maioria desses foi de homens totalizando $60 \%$ dos entrevistados. Na Figura 3 são apresentados os valores que representam a amostra pesquisada. Ficando esta bem aderente ao cenário da população brasileira e número de advogados em atuação no Brasil, no Amazonas e em Manaus.

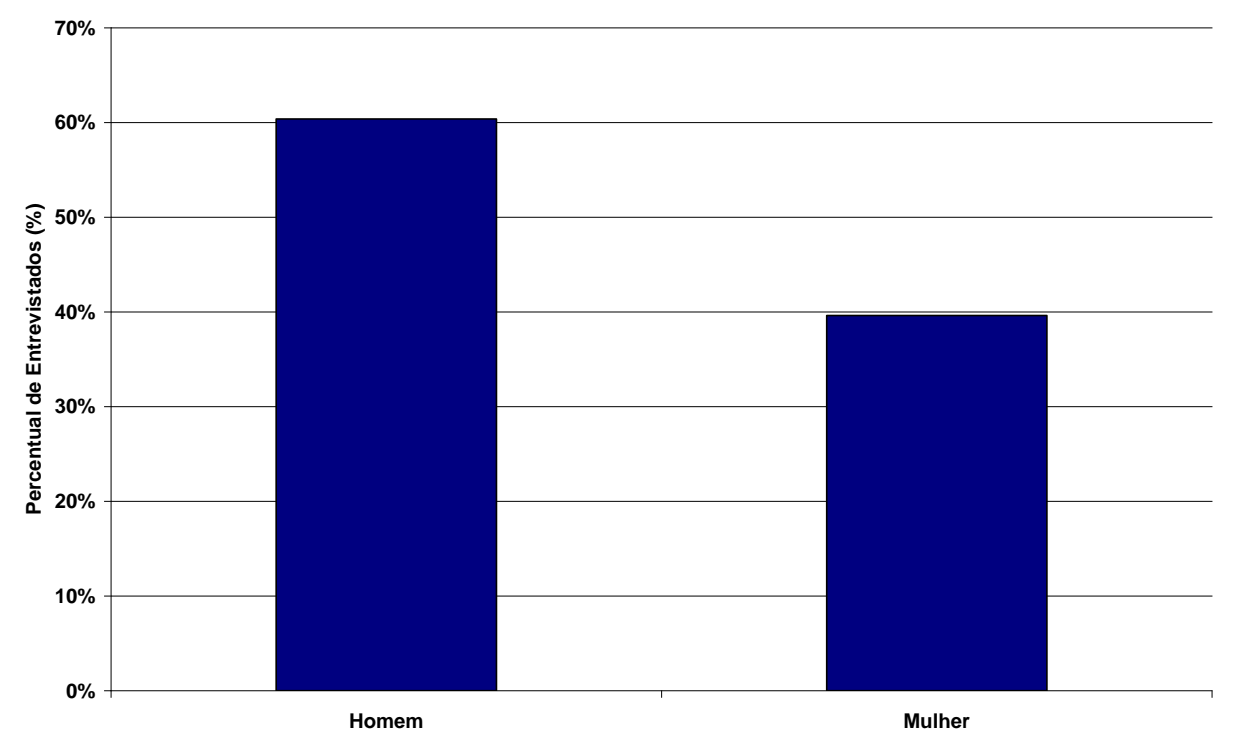

Figura 3 - Sexo dos profissionais entrevistados.

Foram levantados ainda informações quanto ao número de filhos dos entrevistados, entretanto, não se julgou conveniente a análise desses dados como fonte de caracterização dos entrevistados, visto que numa análise mais abrangente não houve nenhuma correlação a cenários modelados ou representativos de classes, extratos ou segmentos da sociedade. Bem como, não se pretendia gerar nenhum juízo de valores quanto aos profissionais pesquisados.

Em relação aos questionamentos foram obtidos os resultados que serão expressos nas figuras a seguir. De início, na Figura 4 são apresentados os relativos ao conceito direto da filiação e sua correlação ao parentesco consangüíneo. Para esta indagação cerca de $9 \%$ dos entrevistados afirmam ser o conceito de filiação uma associação única e exclusiva ao vínculo genético e sanguíneo entre pais e filhos. Tal percentual é considerado elevado, visto que cenários de diferentes modelos de adoção, a regulamentação de direitos e outros fatores já validam a evolução deste conceito. Entretanto, torna-se um ponto de atenção a resistência social que a introdução de novos sistemas familiares introduzem e o que esses geram de antipatia social.

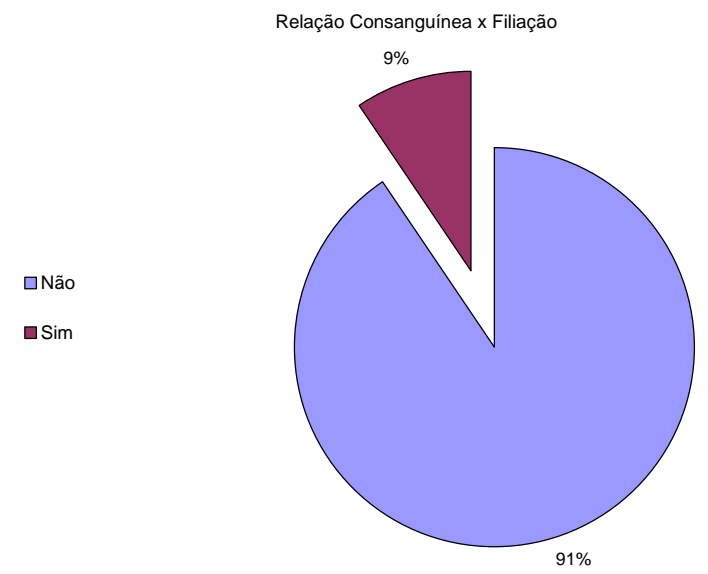

Figura 4 - Respostas a questão: “O conceito de filiação diz respeito apenas a relação consanguínea?”. 
Na Figura 5, surge uma inconsistência no entendimento dos conceitos de filiação e adoção, em especial pelo fato que o percentual para o questionamento "É prudente reconhecer que um processo de adoção é um exemplo de filiação?" foi reduzido a $2 \%$ de recusa ao fato da adoção ser um processo de filiação. Logo, pode-se afirmar que para $7 \%$ dos entrevistados não existe um entendimento pleno dos conceitos de adoção e filiação, bem como, a correlação entre esses. De forma complementar, para $98 \%$ dos entrevistados há o entendimento de que a adoção é um modelo de filiação, que consideram que houve a desbiologização da filiação, ou seja, a substituição do elemento carnal pelo elemento afetivo ou psicológico.

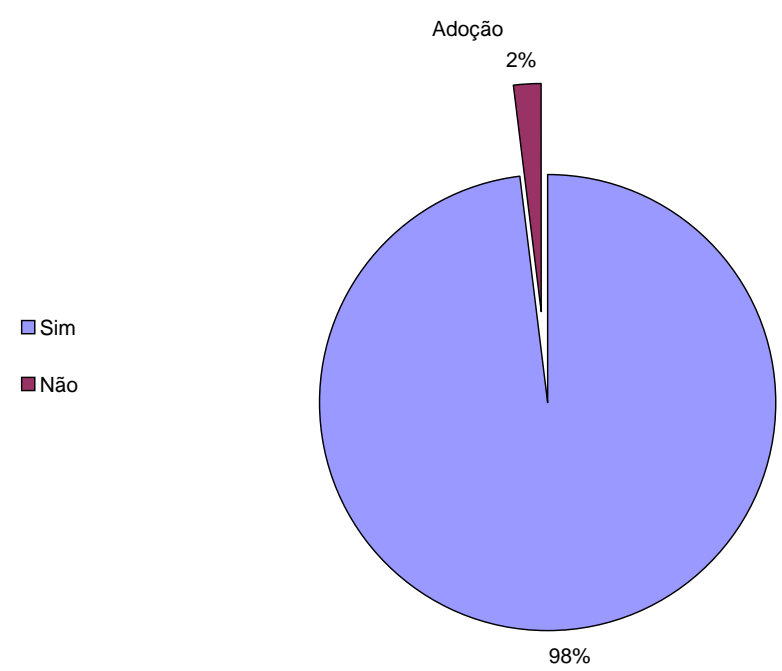

Figura 5 - Respostas a questão: "É prudente reconhecer que um processo de adoção é um exemplo de filiação?".

Nas Figuras 6 e 7 foram avaliados um dos cenários mais polêmicos, inclusive fruto de recente discussão na mídia e em fóruns jurídicos, que é a adoção por homossexuais. Nestes casos foram avaliadas situações práticas que envolvem a adoção por duas mulheres e por dois homens desmembradas em duas questões, principalmente para uma avaliação aprofundada da existência da leitura diferenciada entre os referidos casos. Na Figura 6 são apresentados os resultados para a conformidade dos entrevistados com relação a adoção por duas mulheres, neste gráfico é possível observar percentuais de aceitação da ordem de 59\%. Entretanto, é importante observar que do índice de $41 \%$ da recusa a tal caso, tem-se que $73 \%$ (em termos absolutos $30 \%$ dos entrevistados) representam a opinião de homens.

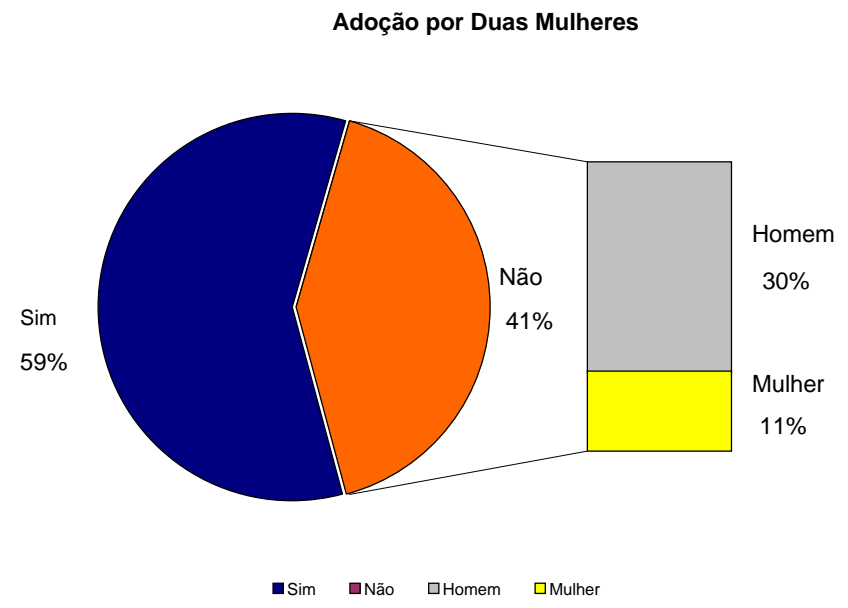

Figura 6 - Respostas a questão: "Você reconhece como um processo de filiação uma adoção feita por um casal composto por 2 mulheres?". 


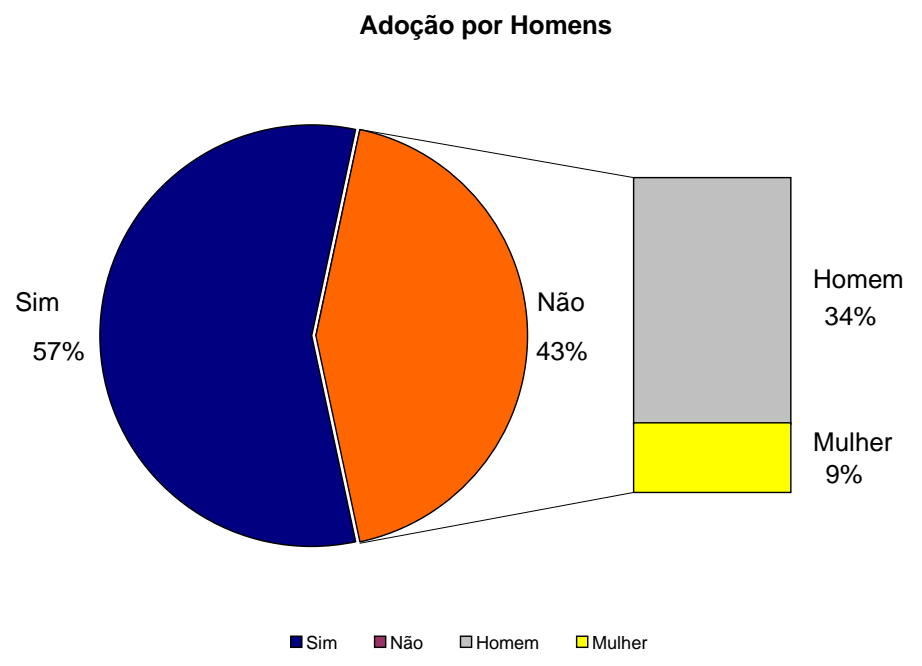

Figura 7 - Respostas a questão: "Você reconhece como um processo de filiação uma adoção feita por um casal composto por dois homens?".

Na Figura 7 observa-se que para cenário de adoção por dois homens o entendimento sobre tal situação é ainda mais reduzido, com $57 \%$ de aprovação por parte dos entrevistados. Havendo a mesma tendência anterior, com 79\% (em termos absolutos de 34\% dos entrevistados), para os profissionais do sexo masculino.

No entanto, o entendimento referente à adoção por homossexuais pode ter sido alterado com a recente decisão do Supremo Tribunal Federal, no reconhecimento da união homoafetiva como entidade familiar, visto que este questionário fora aplicado antes da referida decisão.

Em relação aos casos que envolvem o reconhecimento de pleitos de barrigas de aluguel ou mães de substituição, observou-se que $89 \%$ dos entrevistados entendem que a filiação é de quem cedeu o material genético com o fundamento de que mãe é aquela que fez o planejamento familiar e manifestou o interesse procriacional. E somente $11 \%$ entendem que a filiação é da mãe portadora com o fundamento de que pessoas não podem ser objetos de contrato e que a separação da mãe biológica da criança gerada poderia causar traumas psicológicos. Neste caso, $100 \%$ dos profissionais que deram tal posicionamento são do sexo masculino.

\section{Reconhecimento da Barriga de Aluguel}

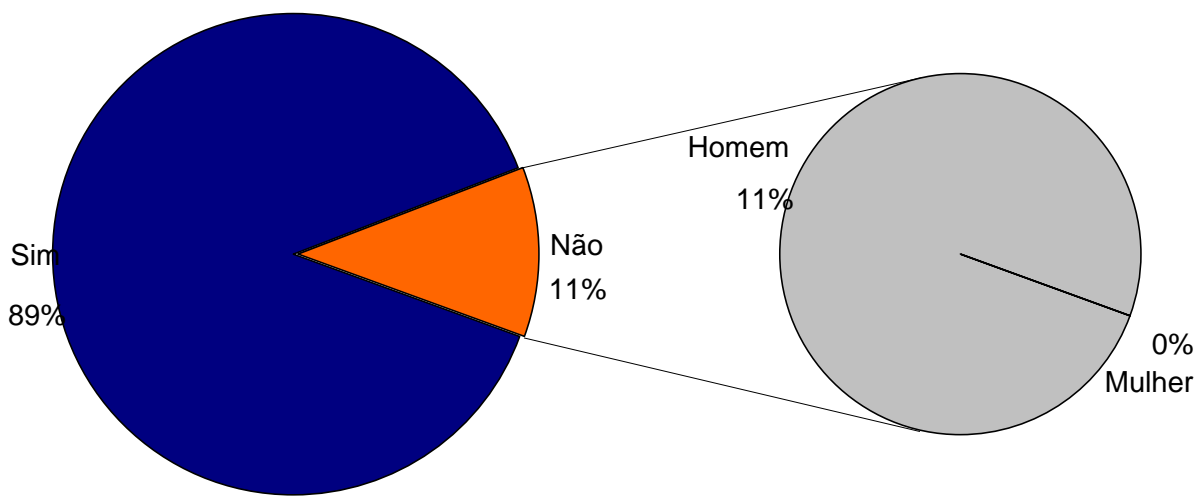

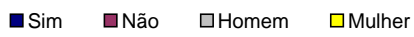


Figura 8 - Respostas a questão: “Num caso em que há inseminação artificial de um casal, numa terceira pessoa que atua como barriga de aluguel, a filiação é elegível para o casal que cedeu o material genético (óvulo fecundado)?".

Evoluindo-se no questionário tem-se o perfil mais relativo a dados históricos e casos práticos vivenciados pelos entrevistados. Nessa esfera, a primeira variável avaliada foi quanto ao perfil e aceitação dos juízes das varas de família da cidade de Manaus e sua propensão a aceitar as exceções cultivadas nesse artigo. Na Figura 9, observa-se um nível de imparcialidade no entendimento da aceitação ou não para tal temática. Não tendo-se como traçar um perfil para tal cenário.

Perfil dos Juízes

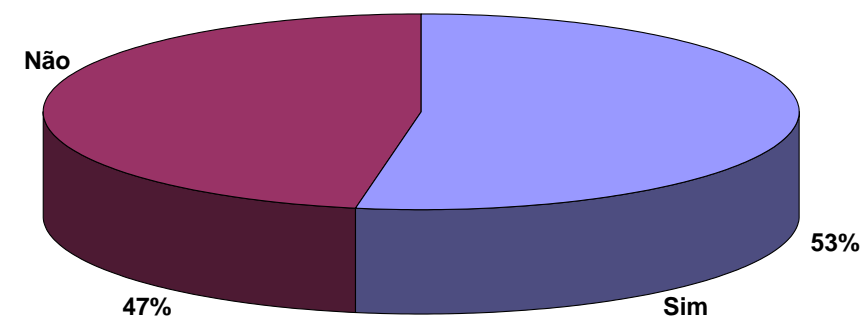

Figura 9 - Respostas a questão: "Você acha que o perfil dos juízes de família Manauenses tendem a considerar as exceções acima para validação dos aspectos relacionados aos pleitos de filiação?".

Considerando a vivência dos entrevistados quanto ao conhecimento dos casos práticos, em relação a existência de situações desse gênero no município, cerca de $25 \%$ dos entrevistados afirmaram que tem conhecimento da ocorrência de pleitos dessa natureza no município, tais dados podem ser observados na Figura 10.

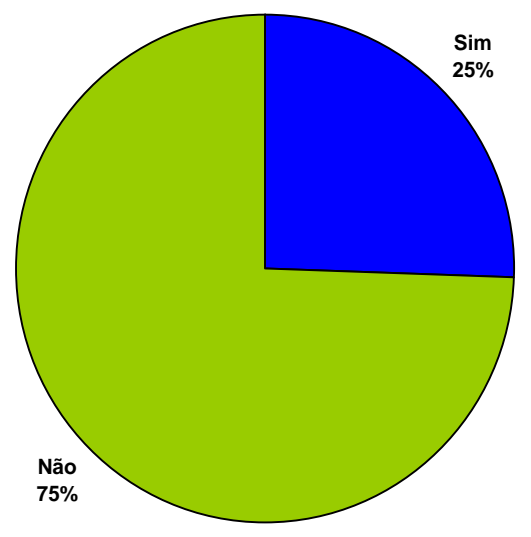

Figura 10 - Respostas a questão: “Você conhece casos práticos de causas ganhas na cidade de Manaus?".

Considerando a atuação dos advogados nessas situações apenas $8 \%$ dos entrevistados atuaram em casos que envolvem exceções ao modelo formal da família. Sendo que desses, $6 \%$ atuaram em situações homoafetivas e $2 \%$ em casos que envolvem pleitos de barrigas de aluguel. 
Tal ilustração desse cenário é mostrada na Figura 11.

Atuação em Causas

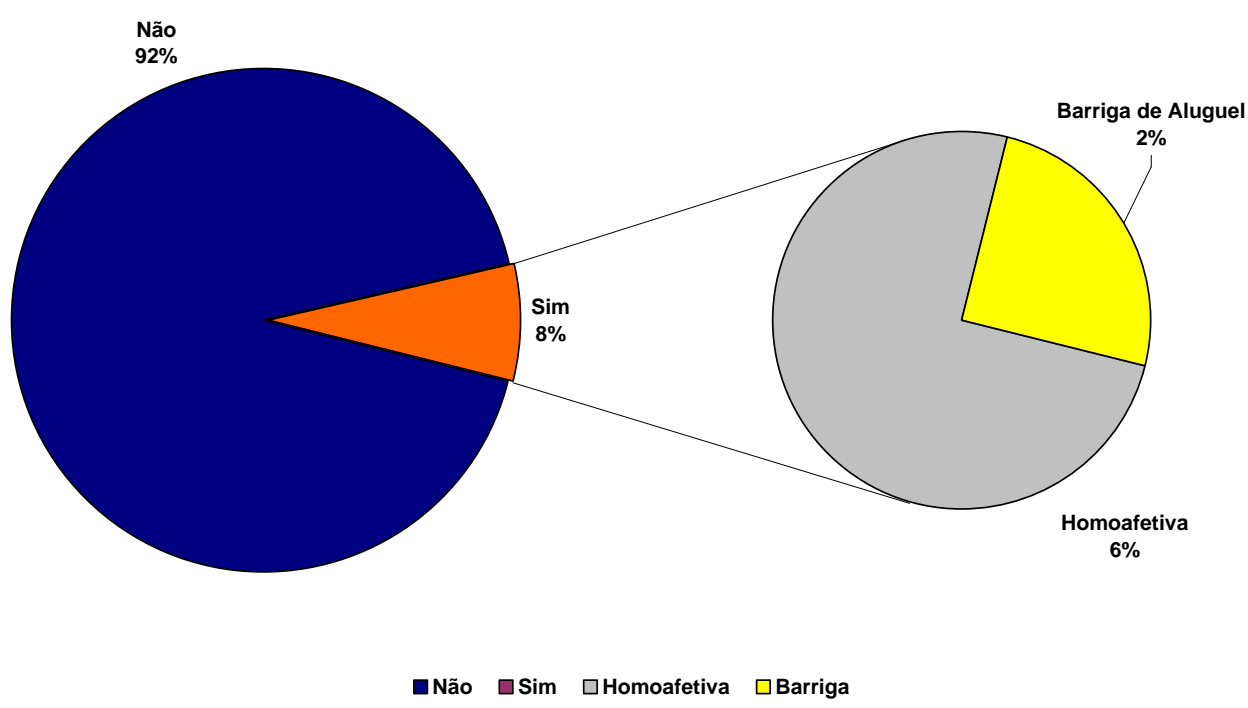

Figura 11 - Respostas a questão: “Você já atuou em casos relacionados a algum dos cenários acima? Qual Cenário?".

Diante desse cenário global, puderam-se observar avanços no desenvolvimento dos novos conceitos de filiação no município de Manaus, havendo uma aceitação razoável e atualização considerável aos novos termos e rumos que a justiça brasileira adota e toma para sua organização.

Por fim, como uma forma de homogeneizar os resultados e criar um índice de favorabilidade ao tema pesquisado, ou seja, exceções ao vinculo denominado de filiação. Nesta seção, foram agrupados os respondentes que demonstram um nível de aderência pleno a todas as questões interrogadas, validando o melhor perfil de atuação para causas dessa natureza.

Observou-se, ainda, que $17 \%$ dos profissionais demonstraram um melhor entendimento e conhecimento sobre o tema, sendo na sua grande maioria, ou seja, $12 \%$, representados por profissionais do sexo feminino. Logo, tem-se o entendimento e podem-se extrapolar os resultados para que o melhor cenário para exploração do tema envolve advogados do sexo feminino, sendo julgados por juízas. Entretanto, tal interpretação é um ponto modelado e validado pelas estatísticas da amostra desenvolvida.

$\mathrm{Na}$ Figura 12 tem-se uma representação gráfica dos índices de favorabilidade mensurados. 


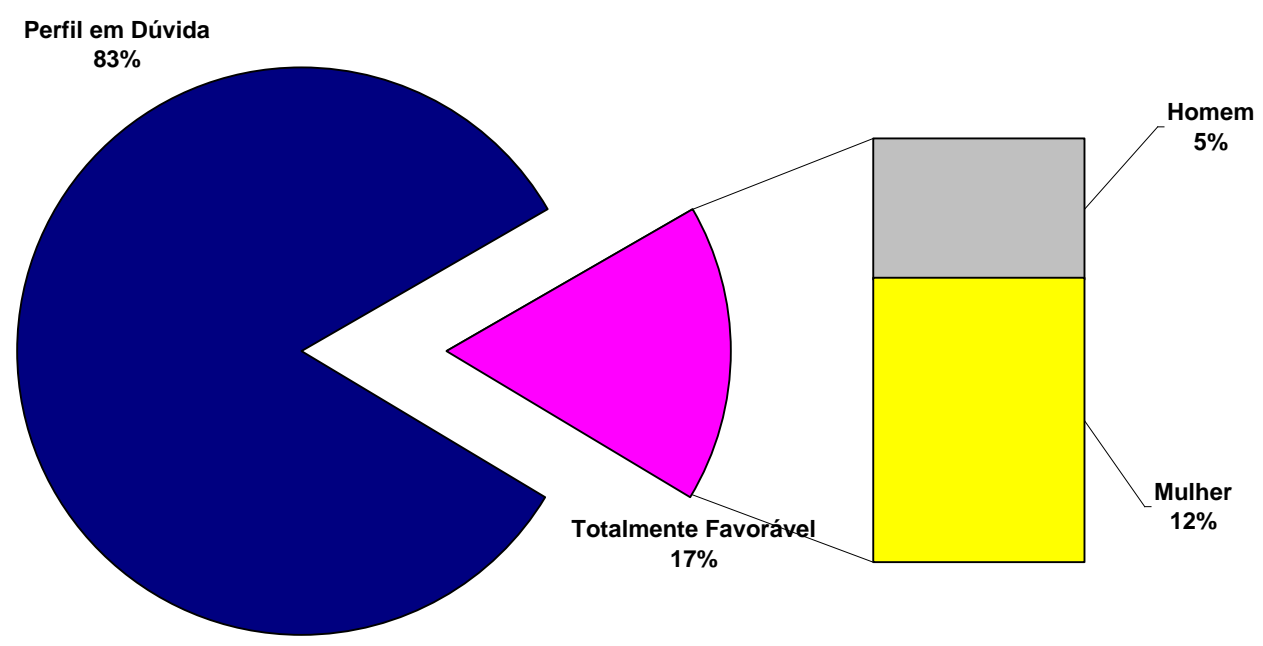

—Perfil em Dúvida $\square$ Perfil Totalmente Favorável $\square$ Homem $\square$ Mulher

Figura 12 - Índice de favorabilidade ao entendimento das exceções como formas de filiação.

\section{CONCLUSÕES}

A partir do desenvolvimento deste trabalho, obtenção dos resultados e do desdobramento das hipóteses desenvolvidas, tem-se as seguintes conclusões:

Foi elaborado um mapeamento do histórico do conceito de filiação ao longo da série temporal da sociedade brasileira, tendo-se um forte embasamento bibliográfico para suportar os principais conceitos relativos a filiação e a legislação vigente. Tendo-se como ponto dessa evolução a atual consagração dos fenômenos sociais no que concerne a relacionamentos homoafetivos, barrigas de aluguel etc.

A correlação entre o desenvolvimento tecnológico e de formas de respostas sociais em relação ao conceito de filiação foi traçada com a descrição da linha de tendência social, e a aceitação as mudanças e avanços sociais e técnicos, obtendo-se dados estatísticos para a realidade do município de Manaus, estado do Amazonas.

Foi possível identificar os diferentes entendimentos por profissionais do sexo masculino e feminino sobre as temáticas abordadas, notando-se uma rejeição pelos homens a modelos homoafetivos e uma favorabilidade integral mais intensa entre as profissionais do sexo feminino.

Em relação aos advogados consultados observou-se que esses tendem a ter posicionamento diferenciado para casos que envolvem pleitos de filiação para casais homoafetivos compostos por mulheres e homens, estando positiva a paternidade ou maternidade para a maioria dos casos, contrariando a hipótese levantada.

Os julgamentos, em Manaus-AM, para questões de filiação onde a geração do feto se deu por meio de recursos de engenharia genética ou inseminação artificial, por um casal convencional, tendem a confirmação da relação de filiação, em especial, para os casos onde ocorre o cenário dos pais e filhos ser consanguíneos.

Ocorre uma baixa favorabilidade para a atualização dos mecanismos jurídicos para 
aceitação das referidas temáticas, visto que não foi observado um entendimento pleno dos conceitos e seus desdobramentos.

\section{REFERÊNCIAS BIBLIOGRÁFICAS}

1. BARROS MONTEIRO, Washington de. Curso de direito civil: direito de família. 17. ed., São Paulo, Saraiva, 1978.

2. BEVILÁQUA, Clóvis. Direito de família. 8 ed.. São Paulo: Freitas Bastos, 1956.

3. BOSCARO, Márcio Antônio. Direito de filiação. São Paulo: revista dos tribunais, 2002.

4. BRASIL. Constituição da República Federativa do Brasil, de 5 de outubro de 1988. Disponível no site: http://www.planalto.gov.br/ccivil_03/Constituicao/Constituicao.htm. Acesso em: $11 / 05 / 2011$.

5. CÂNDIDO, Nathalie Carvalho. Filiação na reprodução assistida heteróloga. Disponível em: http://www.direitonet.com.br/artigos/x/36/70/3670/. Acesso em: 10 set. 2010.

6. CAVALLINI, Viviane Cristina Rodrigues. Paternidade biológica $\times$ paternidade socioafetiva. Disponível em: http://www.conpedi.org.br/arquivos/anais/maringa/15_1232.pdf. Acesso em 11 set. 2010.

7. DINIZ, Maria Helena. Curso de direito civil brasileiro: direito de família. Volume 5,11 a edição. São Paulo: Saraiva, 1996.

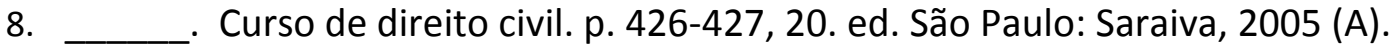

9. Curso de direito civil brasileiro: direito de família. 20. ed. v. 5, São Paulo: Saraiva, 2005 (B).

10. GONÇALVES. Carlos Roberto. Direito civil brasileiro: direito de família. 6 ed. rev. atual, v. 5. São Paulo: Saraiva, 2009.

11. KLINGER FILHO, Domingos Afonso. Considerações acerca dos efeitos jurídicos do uso indevido de material genético. Revista da ESMESC, p. 113-130, v. 14, n. 20, 2007.

12. LEITE, Eduardo de. Procriações artificiais e o direito. Aspectos médicos, religiosos, psicológicos, éticos e jurídicos. Temas de direito de família. São Paulo: Editora Revista dos Tribunais, 1995.

13. LOBO, Paulo Luiz Netto. Direito ao estado de filiação e direito à origem genética: uma distinção necessária. CEJ, v. 8 n. 27, p. 47-56 out./dez. 2004.

14. __ Paulo Luiz Netto. Famílias. São Paulo: Saraiva, 2008.

15. MONTEIRO, Washington de Barros. Curso de Direito Civil - direito de família. 2. vol. 26. ed. São Paulo: Saraiva, 1986.

16. _ Curso de direito civil: direito de família. São Paulo: Saraiva, 1996.

17. NERY JUNIOR, Nelson. Novo código civil e legislação extravagante anotados: atualizado até 15.03.2002. São Paulo: Revista dos Tribunais, 2002. 
18. PEREIRA, Caio Mário da Silva. Instituições de Direito Civil. Volume 5. 11ạ edição. Rio de Janeiro: Forense, 1997.

19. . Reconhecimento de paternidade e seus efeitos. 5. ed. Rio de Janeiro: Forense, 1996.

20. RODRIGUES, Sílvio. Direito civil: direito de família. 6. vol. 17. ed. São Paulo: Saraiva, 1991.

21. . Direito civil: direito de família. 6. vol. 27. ed. São Paulo: Saraiva, 2002.

22. SILVA, E. L.; MENEZES, E. M. Metodologia da pesquisa e elaboração da dissertação. 3o ed. Universidade Federal de Santa Catarina - UFSC: Florianópolis, 2001.

23. SCALQUETTE, Ana Cláudia Silva. Família \& Sucessões. São Paulo: Barros, Fisher \& Associados, 2005.

24. SILVA, De Plácido e. Vocabulário jurídico. 17. ed. Rio de Janeiro: Forense, 2000.

25. VELOSO, Zeno. Direito brasileiro da filiação e paternidade. São Paulo: Malheiros, 1997.

26. VENOSA, Sílvio de Salvo. Direito civil: direito de família. 3. ed. São Paulo: Atlas, 2003. 